\title{
BMJ Open Association between normal tension glaucoma and the risk of Alzheimer's disease: a nationwide population-based cohort study in Taiwan
}

\author{
Yu-Yen Chen,, ${ }^{1,2}$ Yun-Ju Lai, ${ }^{2,3,4}$ Yung-Feng Yen, ${ }^{2,5}$ Ying-Cheng Shen, ${ }^{1}$ \\ Chun-Yuan Wang, ${ }^{1}$ Chiao-Ying Liang, ${ }^{1}$ Keng-Hung Lin, ${ }^{1}$ Lir-Wan Fan ${ }^{6}$
}

To cite: Chen Y-Y, Lai Y-J, Yen Y-F, et al. Association between normal tension glaucoma and the risk of Alzheimer's disease: a nationwide populationbased cohort study in Taiwan. BMJ Open 2018;8:e022987. doi:10.1136/ bmjopen-2018-022987

- Prepublication history and additional material for this paper are available online. To view these files, please visit the journal online (http://dx.doi org/10.1136/bmjopen-2018022987).

Received 17 March 2018 Revised 27 July 2018 Accepted 28 September 2018

Check for updates

(c) Author(s) (or their employer(s)) 2018. Re-use permitted under CC BY-NC. No commercial re-use. See rights and permissions. Published by BMJ.

For numbered affiliations see end of article.

Correspondence to

Dr Yu-Yen Chen;

yuyenchen.phd@gmail.com

\section{ABSTRACT}

Objectives To investigate a possible association between normal tension glaucoma (NTG) and an increased risk of developing Alzheimer's disease (AD).

Design Retrospective cohort study.

Setting NTG group and the comparison group were retrieved from the whole population of the Taiwan National Health Insurance Research Database from 1 January 2001 to 31 December 2013.

Participants A total of 15317 subjects with NTG were enrolled in the NTG group, and 61268 age-matched and gender-matched subjects without glaucoma were enrolled in the comparison group.

Primary and secondary outcome measures KaplanMeier curves were generated to compare the cumulative hazard of $A D$ between the two groups. A multivariable Cox regression analysis was used to estimate the adjusted hazard ratios (HRs) of $A D$, adjusted for diabetes, hypertension, hyperlipidaemia, coronary artery disease and stroke. Furthermore, risk factors for developing $A D$ among the NTG group were investigated.

Results The mean age of the cohort was $62.1 \pm 12.5$ years. Patients with NTG had significantly higher proportions of diabetes, hypertension, hyperlipidaemia, coronary artery disease and stroke than the comparisons. Patients with NTG had a significantly higher cumulative hazard for $A D$ than the comparisons $(p<0.0001)$. In the multivariable Cox regression after adjustment for confounders, the NTG group had a significantly higher risk of $\mathrm{AD}$ (adjusted HR 1.52; 95\% $\mathrm{Cl} 1.41$ to 1.63 ). Moreover, in the NTG group, when we compared the effects of different types of glaucoma eye drops, none of the eye drops used were significant risk factors or protective factors for $A D$. Conclusions People with NTG are at a significantly greater risk of developing $A D$ compared with individuals without glaucoma. Among patients with NTG, none of the glaucoma eye drops used significantly changed the risk of subsequent $A D$.

\section{INTRODUCTION}

Glaucoma is a chronic, progressive disease with characteristics of retinal ganglion cell (RGC) loss, retinal nerve fibre layer (RNFL) thinning and optic nerve atrophy. ${ }^{1-3}$ Elevated
Strengths and limitations of this study

- The study used the comprehensive, whole national population database with a long study period to investigate the relationship between normal tension glaucoma (NTG) and Alzheimer's disease (AD).

- The cohort study design and survival analysis would elucidate the association between NTG and subsequent risk of developing $A D$.

- Possible confounders were adjusted in the Cox regression to derive the more real correlation between NTG and AD.

intraocular pressure (IOP) plays an important role in the development of glaucomatous optic neuropathy. However, 30\%-92\% of primary open-angle glaucoma (POAG) have IOP within the normal range and are classified as normal tension glaucoma (NTG). ${ }^{24-7}$ NTG occurs because of a fragile optic nerve that can be damaged despite a normal IOP, or because of mechanisms other than an elevated IOP (eg, insufficient ocular perfusion pressure or autonomic dysfunction). ${ }^{8-13}$ Without treatment, NTG leads to optic nerve atrophy, progressive visual field loss and even blindness. The mainstay treatment for NTG, similar to the therapy for other types of glaucoma, is aimed at reducing IOP with glaucoma eye drops.

Alzheimer's disease (AD) is the most common form of dementia that is characterised by a progressive loss of memory and cognition and changes in personalities and behaviour, as well as by an impaired ability to perform daily activities. ${ }^{14}$ In the brains of patients with $\mathrm{AD}$, amyloid plaques and neurofibrillary tangles (aggregation of abnormal tau proteins) lead to gross atrophy of the brain. $^{15}$

NTG and AD have common features. Both of them are chronic, progressive 
neurodegenerative diseases with an age-related and female-predominant incidence. ${ }^{16}$ In structural and pathological studies, patients with AD exhibit RGC loss and RNFL thinning, similar to patients with NTG. ${ }^{17-20}$ In genetic studies, the epsilon 4 allele of apolipoprotein $\mathrm{E}$ (APOE), which is a risk factor for late-onset $\mathrm{AD}$, has been observed in the pathogenesis of NTG. ${ }^{21}$ The optineurin gene has also been found to be associated with both $\mathrm{AD}$ and NTG. ${ }^{22}{ }^{23}$ In addition, in clinical, cross-sectional studies, Bayer and Tamura et al have found an increased prevalence of glaucoma in patients with $\mathrm{AD} .{ }^{24-26}$ All of these may imply that glaucoma and $\mathrm{AD}$ share similar pathophysiological or underlying mechanisms.

However, population-based cohort studies evaluating the association between glaucoma and $\mathrm{AD}$ have revealed inconsistent findings. The Three-City-Bordeaux-Alienor study conducted in France showed that patients with open-angle glaucoma (OAG) were four times more likely to develop dementia during the 3-year period. ${ }^{27}$ In a Taiwan registry study, Lin $e t$ al also found a significantly higher risk of developing $\mathrm{AD}$ among the POAG patients. ${ }^{28}$ In contrast, there was no increased risk of developing $\mathrm{AD}$ among the NTG patients in a Danish registry study and among the patients with POAG in a population-based study in Sweden. ${ }^{2930}$ The discrepancies may be due to the insufficient statistical power, non-equivalent study designs and different diagnostic criteria.

The objective of our study was to investigate whether patients with NTG have a higher risk of developing $\mathrm{AD}$ than controls using the National Health Insurance Research Database (NHIRD) in Taiwan. We used the whole population database, and therefore had large numbers of patients and a high level of statistical power. In addition, the NHIRD adopted the International Classification of Diseases, Ninth Revision, Clinical Modification (ICD-9-CM) codes, which are generally accepted worldwide. Thus, our results can be clearly interpreted and compared with further studies in other countries.

\section{MATERIALS AND METHODS \\ Data source}

The National Health Insurance (NHI) programme of Taiwan covers the healthcare services of greater than 99\% of Taiwan's 23 million residents. The NHIRD is maintained by the National Health Research Institutes of Taiwan and includes inpatient and outpatient medical benefit claims. In NHIRD, the diagnoses were accurate and were verified by the National Health Administration (NHA). The NHA not only checks the consistencies between the claimed data and the charts but also makes sure the patient received a standard protocol of examinations to confirm the diagnoses. To ensure confidentiality, the identification of all patients in the database was encrypted prior to releasing data for research purposes. Therefore, according to the rules of the Institutional Review Board, written informed consent was waived. Based on the healthcare claims of the entire population, we sought to compare the hazard of $\mathrm{AD}$ in subjects with and without NTG during the 13-year period.

\section{Patient involvement}

Patients were not directly involved in the design of this study.

\section{Inclusion and exclusion criteria}

Using the Taiwan NHIRD from 1996 to 2013, we performed a retrospective cohort study. We first selected patients with NTG (ICD-9-CM codes 365.12) from 1 January 2001 to 31 December 2013. Patients with NTG diagnoses from 1 January 1996 to 31 December 2000 were excluded to ensure that our patients with NTG were newly diagnosed. The date of the first NTG claim was defined as the index date. Those who had never received a diagnosis of glaucoma were randomly selected as a comparison group at a ratio of 1:4 and matched with the NTG group on age, gender and index year (the year of the index date or enrolment). The two groups were followed up to see whether they developed subsequent AD. Follow-up time was calculated from the index date (enrolment date) to the date of $\mathrm{AD}$ diagnosis, death or the end of 2013, whichever occurred first. The diagnosis of $\mathrm{AD}$ (ICD-9-CM codes: 331.0) was confirmed by neurologists or psychiatrists through a well-acknowledged, standard diagnostic protocol. Subjects who received a diagnosis of $\mathrm{AD}$ or dementia before the index date or enrolment were excluded to ensure that the occurrence of $\mathrm{AD}$ was newly diagnosed.

\section{Statistical analysis}

After investigating the two groups descriptively by age, gender and comorbidities, the group differences were analysed by the two-sample t-test (for continuous variables) and $\chi^{2}$ test (for categorical variables). Survival analysis using the Kaplan-Meier method with the log-rank test was applied to describe and compare the cumulative incidence curves of $\mathrm{AD}$. A Cox proportional hazard model was used to estimate the hazard ratio (HR) for the occurrence of $\mathrm{AD}$ according to each variable in the univariate and multivariate analyses. Variables included in the regression analysis were age, gender and comorbidities, including diabetes, hypertension, hyperlipidaemia, coronary artery disease and stroke. Comorbidities were regarded as time-dependent covariates.

We additionally performed stratified analyses according to age, in order to evaluate the risk factors for $\mathrm{AD}$ among different age subgroups. Then, using Cox proportional hazard model, we also explored the relationship between high-tension glaucoma (HTG) and AD, as well as the relationship between NTG and all dementia/dementia other than $\mathrm{AD}$.

Subsequently, we focused on the NTG group. The Cox regression was used to identify the risk factors associated with AD among patients with NTG. Variables included for analysis were age, gender, comorbidities and different types of glaucoma eye drops. Glaucoma eye drops were 


\begin{tabular}{|c|c|c|c|}
\hline Variable & $\begin{array}{l}\text { NTG group } \\
n=15317\end{array}$ & $\begin{array}{l}\text { Comparison } \\
\text { group } n=61268\end{array}$ & P values \\
\hline & n (\%) & n (\%) & \\
\hline $\begin{array}{l}\text { Age, year, } \\
(\text { mean } \pm \text { SD) }\end{array}$ & $62.1 \pm 12.5$ & $62.1 \pm 12.5$ & 1.000 \\
\hline Age, categorical & & & 1.000 \\
\hline$<55$ & $4778(31.2)$ & 19112 (31.2) & \\
\hline $55-65$ & $3889(25.4)$ & $15556(25.4)$ & \\
\hline $65-75$ & $3627(23.7)$ & 14508 (23.7) & \\
\hline$\geq 75$ & $3023(19.7)$ & $12092(19.7)$ & \\
\hline Gender & & & 1.000 \\
\hline Male & $8372(54.7)$ & $33488(54.7)$ & \\
\hline Female & $6945(45.3)$ & $27780(45.3)$ & \\
\hline \multicolumn{4}{|l|}{ Comorbidities } \\
\hline Diabetes & $5110(33.4)$ & $15671(25.6)$ & $<0.0001$ \\
\hline Hypertension & $9148(59.7)$ & $32790(53.5)$ & $<0.0001$ \\
\hline Hyperlipidaemia & $7590(49.6)$ & 21628 (35.3) & $<0.0001$ \\
\hline $\begin{array}{l}\text { Coronary artery } \\
\text { disease }\end{array}$ & $5627(36.7)$ & $16323(26.6)$ & $<0.0001$ \\
\hline Stroke & $1572(10.3)$ & $6518(10.6)$ & 0.18 \\
\hline $\begin{array}{l}\text { Follow-up period, } \\
\text { year (mean } \pm S D \text { ) }\end{array}$ & $4.92 \pm 3.29$ & $4.96 \pm 3.27$ & 0.18 \\
\hline $\begin{array}{l}\text { Occurrence of } A D \\
\text { during the follow-up } \\
\text { period }\end{array}$ & $1023(6.7)$ & $2574(4.2)$ & $<0.0001$ \\
\hline
\end{tabular}

AD, Alzheimer's disease; NTG, normal tension glaucoma.

identified and classified by the National Drug Code and the Anatomic Therapeutic Chemical code. According to the classification system, types of glaucoma eye drops include $\alpha$-agonists, parasympathomimetics (pilocarpine), carbonic anhydrase inhibitors, $\beta$-blockers, prostaglandin analogues and fixed combinations. All statistical operations were performed using SAS statistical package, V.9.2 (SAS Institute, Cary, North Carolina, USA).

\section{RESULTS}

\section{Demographic characteristics of the study sample}

A total of 15317 patients NTG and 61268 matched controls were enrolled in the study. Table 1 displays the demographics of the two groups. The mean age in both groups was 62.1 years. The NTG group had a significantly higher proportion of diabetes, hypertension, hyperlipidaemia, coronary artery disease and stroke than the comparison group. During the 13-year study period, the cumulative incidence of $\mathrm{AD}$ was significantly higher in the NTG group $(1023 / 15317 ; 6.7 \%)$ than in the comparison group (2574/61 268; 4.2\%). Age of AD onset was $73.8 \pm 8.1$ years.

\section{Cumulative hazard curves by the Kaplan-Meier method}

Figure 1 illustrates the cumulative hazard curves for AD in the NTG group and the comparison group. A log-rank

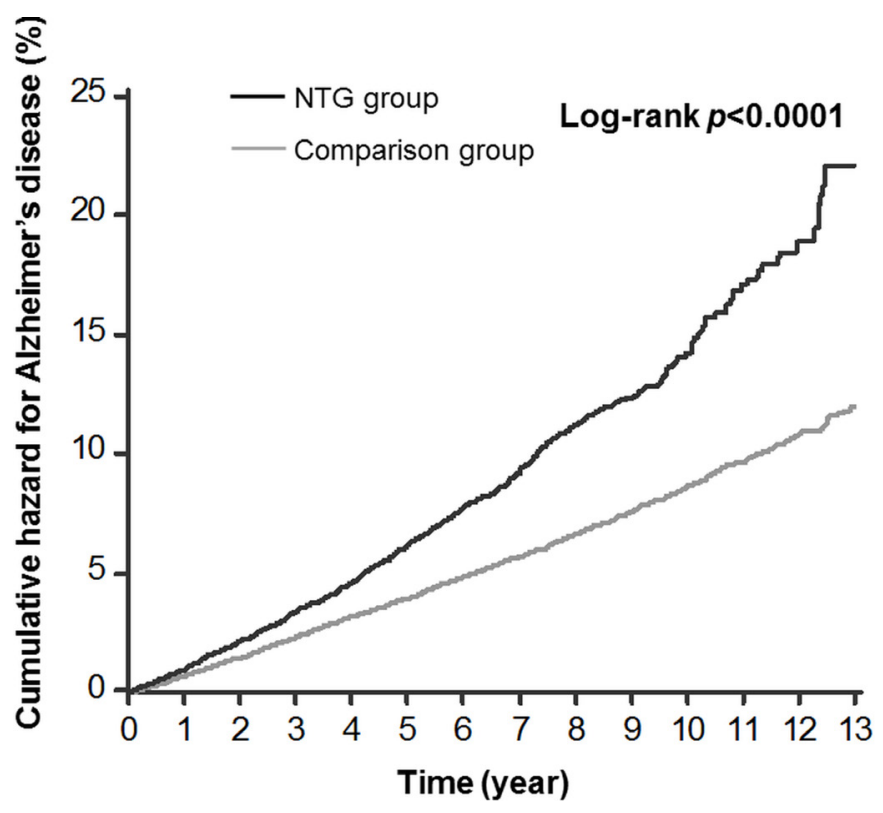

Figure 1 Kaplan-Meier curves for Alzheimer's disease among patients with normal tension glaucoma (NTG) and the comparison group. The black line represents the NTG group and the grey line represents the comparison group.

test revealed a statistically significant difference between the hazard curves of the two groups ( $p$ value $<0.0001$ ).

\section{Univariate and multivariate analyses by the Cox regression model}

The unadjusted $\mathrm{HR}$ for $\mathrm{AD}$ was 1.66 times greater in the NTG group than in the comparison group (95\% CI 1.55 to 1.79 ) (table 2). After adjusting for covariates, the significantly greater HR for AD in the NTG group remained (adjusted HR 1.52; 95\% CI 1.41 to 1.63). Age was a significant risk factor for $\mathrm{AD}$ in both the univariate and multivariate analyses. The adjusted $\mathrm{HR}$ for $\mathrm{AD}$ in patients over 75 years old reached 38.85 when compared with those patients younger than 55 years old. Men were less likely to develop AD than women (adjusted HR 0.92; $95 \%$ CI 0.86 to 0.98 ). In the univariate analysis, patients with diabetes, hypertension, hyperlipidaemia, coronary artery disease or stroke had a significantly higher risk of developing AD. After adjustment for the covariates, only stroke remained a significant risk factor for $\mathrm{AD}$ (adjusted HR $1.73 ; 95 \%$ CI 1.61 to 1.87 ). In online supplementary table 1, subgroup analyses were also presented among individuals with older and younger age separately. Among subjects younger than 65 , the adjusted $\mathrm{HR}$ for $\mathrm{AD}$ was 1.98 times greater in the NTG group than in the comparison group (95\% CI 1.63 to 2.42); the other independent, significant risk factors for $\mathrm{AD}$ were female gender and stroke. Among subjects older than 65 , in addition to these risk factors, diabetes also significantly increased the risk for $\mathrm{AD}$ (adjusted HR 1.02; 95\% CI 1.01 to 1.12).

Regarding the association between HTG and AD, the HR was non-significant (adjusted HR 1.12; 95\% CI 0.89 to 1.36 ). In table 3 , the relationship between NTG and dementia other than $\mathrm{AD}$ was also non-significant (adjusted 
Table 2 Analysis of risk factors for Alzheimer's disease in patients with and without normal tension glaucoma

\begin{tabular}{|c|c|c|c|c|}
\hline \multirow[b]{2}{*}{ Predictive variables } & \multicolumn{2}{|l|}{ Univariate analysis } & \multicolumn{2}{|l|}{ Multivariate analysis } \\
\hline & $\begin{array}{l}\text { Unadjusted HR } \\
(95 \% \mathrm{Cl})\end{array}$ & $P$ values & $\begin{array}{l}\text { Adjusted HR } \\
(95 \% \mathrm{Cl})\end{array}$ & $P$ values \\
\hline \multicolumn{5}{|l|}{ Age } \\
\hline$<55$ & Reference & & Reference & \\
\hline$\geq 75$ & 47.85 (38.92 to 58.82$)$ & $<0.0001$ & 38.85 (31.43 to 48.02$)$ & $<0.0001$ \\
\hline Gender (male vs female) & 0.81 (0.76 to 0.87 ) & $<0.0001$ & 0.92 (0.86 to 0.98$)$ & 0.01 \\
\hline \multicolumn{5}{|l|}{ Comorbidities } \\
\hline Diabetes & 1.56 (1.45 to 1.66$)$ & $<0.0001$ & 1.05 (0.98 to 1.13$)$ & 0.20 \\
\hline Stroke & 3.39 (3.16 to 3.64$)$ & $<0.0001$ & 1.73 (1.61 to 1.87$)$ & $<0.0001$ \\
\hline
\end{tabular}

NTG, normal tension glaucoma.

In the multivariate analysis, all the other variables listed in the table were included for adjustment.

HR 1.21; $95 \%$ CI 0.90 to 1.49 ). However, diabetes significantly increased the risk for dementia other than $\mathrm{AD}$ (adjusted HR 2.16; 95\% CI 2.03 to 2.26).

\section{Risk factors for AD among patients with NTG}

Table 4 displays the risk factors for $\mathrm{AD}$ among patients with NTG. Older age, female gender and stroke significantly increased the risk of developing $\mathrm{AD}$ among patients with NTG in univariate as well as multivariate Cox regression analyses. Moreover, when we compared the effects of different types of glaucoma eye drops, none of them were significant risk factors or protective factors for $\mathrm{AD}$.

\section{DISCUSSION}

We conducted a 13-year cohort study on population-based data from the Taiwan NHIRD. Compared with those without glaucoma, patients with NTG had a significantly higher risk (HR 1.52) of developing $\mathrm{AD}$ after adjustment for age, gender and comorbidities. Among patients with NTG, older age, female gender and stroke were significant risk factors for developing AD. However, the types of glaucoma eye drops were not risk factors or protective factors for AD among patients with NTG.

Both NTG and HTG belong to POAG. They present a continuum of POAG, in which the underlying mechanism shifts from predominantly elevated IOP in HTG to haemodynamic changes in NTG. Lee et al conducted a cross-sectional study in South Korea and found that patients with NTG had a significantly higher prevalence of hypertension, hyperlipidaemia, ischaemic heart disease and metabolic syndrome. ${ }^{31}$ These findings are compatible with our findings in table 1 . Compared with patients with non-NTG, we also found that patients with NTG tended to be older and female predominant. These findings are consistent with the previous literature. ${ }^{16}$

Previous studies regarding the relationship between glaucoma and $\mathrm{AD}$ have mostly investigated the association between POAG and AD. ${ }^{272832-34}$ Nevertheless, POAG includes NTG and HTG, which are distinctive disease entities. NTG has different features compared with HTG,

Table 3 Analyses of risk factors for all dementia and dementia other than Alzheimer's disease

\section{Outcome variables}

\begin{tabular}{|c|c|c|c|c|}
\hline \multirow[b]{3}{*}{ Predictive variables } & \multicolumn{2}{|l|}{ All dementia } & \multicolumn{2}{|c|}{$\begin{array}{l}\text { Dementia other than } \\
\text { AD }\end{array}$} \\
\hline & Adjusted HR & & Adjusted HR & \\
\hline & $(95 \% \mathrm{Cl})$ & $P$ values & $(95 \% \mathrm{Cl})$ & $P$ values \\
\hline NTG (yes vs no) & 1.39 (1.25 to 1.46$)$ & $<0.0001$ & 1.21 (0.90 to 1.49$)$ & 0.25 \\
\hline Diabetes & 1.51 (1.47 to 1.54$)$ & $<0.0001$ & 2.16 (2.03 to 2.26$)$ & $<0.0001$ \\
\hline
\end{tabular}

Variables included in the multivariate Cox regression: NTG, age, gender, diabetes, hyperlipidaemia, coronary artery disease, stroke. $\mathrm{AD}$, Alzheimer's disease; NTG, normal tension glaucoma. 
Table 4 Analysis of risk factors for AD among patients with normal tension glaucoma

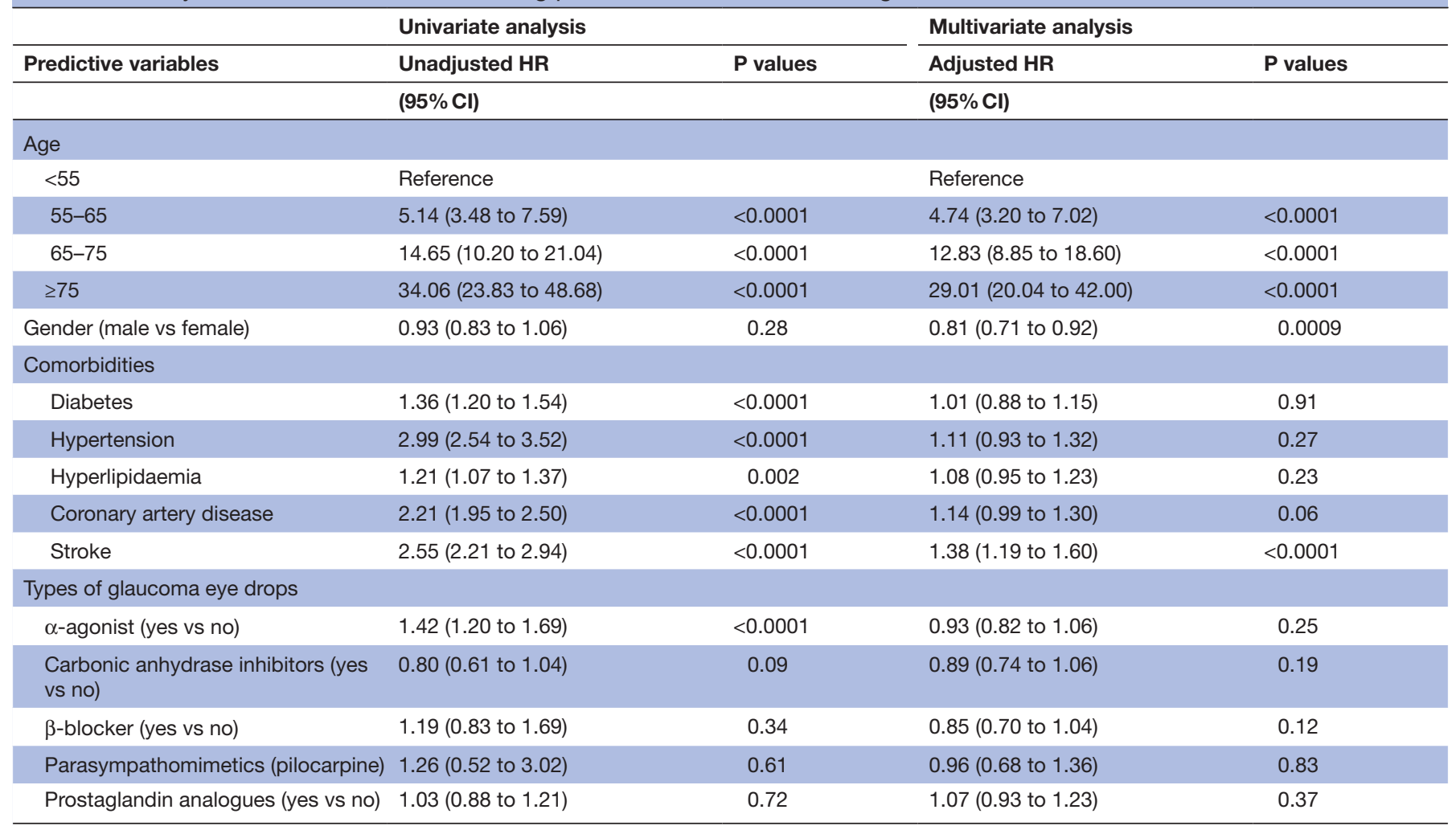

In the multivariate analysis, all the other variables listed in the table were included for adjustment.

such as IOP-independent mechanisms and characteristic patterns of structural/functional damage. ${ }^{31}{ }^{35}$ Therefore, it is not clear enough to regard NTG and HTG as one to evaluate the subsequent risk of $\mathrm{AD}$. One strength of our study is that we specified the association between NTG and AD. To the best of our knowledge, only one previous population-based study focused on the relationship between NTG and AD. ${ }^{29}$ Bach-Holm et al tracked 69 patients with NTG in Denmark for a mean follow-up period of 12.7 years and did not find any significantly higher risk of developing dementia/AD compared with the general population. In fact, none of those 69 patients with NTG subsequently developed AD. Statistically, the case numbers were too small to perform analyses effectively. It is another strength of our study that we included over 15000 patients with NTG from our nationwide database. Thus, we have a higher statistical power to draw convincing conclusions.

Another strength of our study is the adjustment for possible confounders in the Cox regression. Table 2 shows that the unadjusted HR for AD is 1.66 (95\% CI 1.55 to 1.79) in the NTG group compared with the comparison group. Age, female gender and vascular/metabolic comorbidities have been reported to be risk factors of both NTG and AD. ${ }^{1631} 3637$ Thus, these should be adjusted for as confounders to address the association between NTG and AD. Due to the completeness of our database, we obtained inpatient and outpatient medical records of the whole population. After adjustment for confounders, the association between NTG and AD was still significant (HR 1.52; 95\% CI 1.41 to 1.63), providing evidence that the significant association between NTG and AD is a real phenomenon.

Another strength is that we concentrated on the NTG group to investigate the risk factors for AD. Table 4 shows that among patients with NTG, age, female gender and stroke significantly increased the risk of subsequent $\mathrm{AD}$. To the best of our knowledge, this is the first study to find factors that were associated with an increased risk of subsequent $\mathrm{AD}$ among patients with NTG. This finding reminds us to be alert when we identify these high-risk factors among patients with NTG.

Previous animal and in vitro studies have revealed that betaxolol and brimonidine eye drops are neuroprotective. ${ }^{38-42}$ However, in our study, none of the glaucoma eye drops were identified as risk factors or protective factors for AD among the patients with NTG. Further studies are warranted to investigate the issue.

In our study, table 3 shows diabetes is a significant risk factor for dementia other than $\mathrm{AD}$ (mostly are vascular dementia). This finding is consistent with the previous hospital-based study in Taiwan, which revealed a significant association between diabetes and vascular dementia. ${ }^{43}$ On the other hand, our study shows diabetes is not a significant risk factor for $\mathrm{AD}$ among all the enrolled subjects (adjusted HR 1.05, 95\% CI 0.98 to 1.13). However, previous studies found diabetes to be a significant risk factor for $\mathrm{AD}$ among the elderly. ${ }^{44-46}$ To unravel 
the possible interaction effect of age and diabetes on $\mathrm{AD}$, we performed the Cox regression in subgroups according to younger age and older age. Among those over 65 years, diabetes significantly increased the risk of $\mathrm{AD}$, which was compatible with the results of previous studies. ${ }^{44-46}$ Even so, the HR in our study (1.02) was lower than the previous population-based study in Taiwan, which had the study period from 1997 to 2007 and revealed a HR of $1.76(95 \%$ CI 1.50 to 2.07$).{ }^{47}$ The weaker association might result from the better diabetes care in recent years. ${ }^{48}$ Since poor-controlled fasting plasma glucose and $\mathrm{HbA}_{1 c}$ are significant predictors of $\mathrm{AD},{ }^{49}$ the better diabetes care might possibly reduce the development of AD. Our study had a more recent study period (from 2001 to 2013); therefore, the association between diabetes and $\mathrm{AD}$ is weaker. The postulation should be investigated in future studies.

In our investigation regarding the association between HTG and AD, as well as the relationship between NTG and dementia other than $\mathrm{AD}$, the adjusted HR is 1.12 (95\% CI 0.89 to 1.36 ) and 1.21 (95\% CI 0.90 to 1.49 ), respectively. Thus, the significantly positive association was specifically exhibited between NTG and AD. One of the possible explanation is the common pathogenesis of neurotoxic substances in NTG and AD. AD is characterised by abnormal hyperphosphorylated tau and b-amyloid in the brain. These abnormal protein are also related to RGC death in glaucoma. ${ }^{50}$ Another pathological explanation may be the low intracranial pressure (ICP) in both NTG and AD. Low ICP leads to cerebrospinal fluid (CSF) circulatory failure and accumulation of neurotoxins in CSF as well as along the optic nerve, thus playing a role in NTG and AD. ${ }^{51-54}$

From our study, we cannot conclude that NTG or its treatment causes $\mathrm{AD}$, because the association of the two diseases may result from their common pathogenesis. In figure 1, the two lines converge from the outset without any latent period, suggesting the same risk factors that influence NTG also influence AD. Further studies are warranted to elucidate the explanations of relationship between NTG and AD.

A limitation of our study is that NHIRD does not provide information regarding the severity of visual field defects or visual acuity. Therefore, we could not evaluate whether the risk of $\mathrm{AD}$ was positively correlated with the severity of NTG or visual impairment. Future studies including chart review will be conducted to consider these factors. Another limitation is NTG or AD may be underdiagnosed in database studies. Thus, those with NTG may have more healthcare visits, leading to a higher chance of being diagnosed AD. Fortunately, in our healthcare system, NHI covers the fee of the comprehensive, regular health check-up of all beneficiaries. Individuals over 40 years are compelled to receive health check-up once per 3 years and those over 65 years should have once per year. The high accessibility of healthcare ensures the similar chance of diagnosis in NTGs and comparisons if they had $\mathrm{AD}$. It is proved by the similar frequencies of healthcare professionals contacts (excluding ophthalmologists contacts) in NTG and control subjects $(10.2 \pm 7.6$ vs $10.0 \pm 7.7$ times per year; $p=0.08$ ). Even if $\mathrm{NTG}$ and $\mathrm{AD}$ are underdiagnosed, the misclassification is non-differential and causes toward-the-null bias.

The findings from our study have both clinical and public health implications. Clinically, when treating patients with NTG, ophthalmologists need to focus not only on the medical aspects of NTG but also on changes in cognitive function or memory. Patients with NTG at a higher risk for $\mathrm{AD}$, such as older patients, female patients and patients with stroke, should be referred to a neurologist or psychiatrist if early signs of $\mathrm{AD}$ become apparent. From a public health perspective, policy makers are encouraged to enforce screening for $\mathrm{AD}$ risk in patients with NTG and to provide more substantial and integrated care.

\section{Author affiliations}

${ }^{1}$ Department of Ophthalmology, Taichung Veterans General Hospital, Taichung, Taiwan

${ }^{2}$ School of Medicine, National Yang-Ming University, Taipei, Taiwan

${ }^{3}$ Division of Endocrinology and Metabolism, Department of Internal Medicine, Puli

Branch of Taichung Veterans General Hospital, Nantou, Taiwan

${ }^{4}$ Department of Exercise Health Science, National Taiwan University of Sport, Taichung, Taiwan

${ }^{5}$ Section of Infectious Diseases, Taipei City Hospital, Taipei, Taiwan

${ }^{6}$ Department of Pediatrics; Division of Newborn Medicine, University of Mississippi Medical Center, Jackson, Mississippi, USA

Contributors Conceptualisation: Y-YC, Y-JL, Y-FY, Y-CS and L-WF; formal analysis: Y-YC, Y-JL, C-YW and L-WF; investigation: Y-YC, C-YW, C-YL, K-HL and L-WF; methodology: Y-YC, Y-JL, Y-FY and Y-CS; Validation: Y-YC, Y-FY and K-HL; writing the original draft: $Y-Y C$ and L-WF.

Funding The authors have not declared a specific grant for this research from any funding agency in the public, commercial or not-for-profit sectors.

Competing interests None declared.

Patient consent Not required.

Ethics approval This study has been approved by the institutional review board of National Yang-Ming University (2015A018).

Provenance and peer review Not commissioned; externally peer reviewed.

Data sharing statement Data are available from the National Health Insurance Research Database (NHIRD) published by Taiwan National Health Insurance (NHI) Bureau. The data used in this study cannot be made available in the manuscript, the supplemental files or in a public repository due to the Personal Information Protection Act executed by Taiwan's government, starting from 2012. Requests for data can be sent as a formal proposal to the NHIRD (http://nhird.nhri.org.tw) or by email to wt.gro.irhn@drihn.

Open access This is an open access article distributed in accordance with the Creative Commons Attribution Non Commercial (CC BY-NC 4.0) license, which permits others to distribute, remix, adapt, build upon this work non-commercially, and license their derivative works on different terms, provided the original work is properly cited, appropriate credit is given, any changes made indicated, and the use is non-commercial. See: http://creativecommons.org/licenses/by-nc/4.0/.

\section{REFERENCES}

1. Gordon MO, Beiser JA, Brandt JD, et al. The Ocular Hypertension Treatment Study: baseline factors that predict the onset of primary open-angle glaucoma. Arch Ophthalmol 2002;120:714-20.

2. Sommer A, Tielsch JM, Katz J, et al. Relationship between intraocular pressure and primary open angle glaucoma among white and black Americans. The Baltimore Eye Survey. Arch Ophthalmol 1991;109:1090-5.

3. Weih LM, Nanjan M, McCarty CA, et al. Prevalence and predictors of open-angle glaucoma: results from the visual impairment project. Ophthalmology 2001;108:1966-72. 
4. Bonomi L, Marchini G, Marraffa M, et al. Prevalence of glaucoma and intraocular pressure distribution in a defined population. The EgnaNeumarkt Study. Ophthalmology 1998;105:209-15.

5. Cho HK, Kee C. Population-based glaucoma prevalence studies in Asians. Surv Ophthalmol 2014;59:434-47.

6. Klein BE, Klein R, Sponsel WE, et al. Prevalence of glaucoma. The Beaver Dam Eye Study. Ophthalmology 1992;99:1499-504.

7. Rotchford AP, Johnson GJ. Glaucoma in Zulus: a populationbased cross-sectional survey in a rural district in South Africa. Arch Ophthalmol 2002;120:471-8.

8. Caprioli J, Coleman AL; Blood pressure, perfusion pressure, and glaucoma. Am J Ophthalmol 2010;149:704-12.

9. Flammer J, Konieczka K, Flammer AJ. The primary vascular dysregulation syndrome: implications for eye diseases. Epma $J$ 2013;4:14.

10. Mozaffarieh M, Flammer J. New insights in the pathogenesis and treatment of normal tension glaucoma. Curr Opin Pharmacol 2013;13:43-9.

11. Park HY, Park SH, Park CK. Central visual field progression in normal-tension glaucoma patients with autonomic dysfunction. Invest Ophthalmol Vis Sci 2014;55:2557-63.

12. Siaudvytyte L, Januleviciene I, Daveckaite A, et al. Literature review and meta-analysis of translaminar pressure difference in open-angle glaucoma. Eye 2015;29:1242-50.

13. Mroczkowska S, Benavente-Perez A, Negi A, et al. Primary open-angle glaucoma vs normal-tension glaucoma: the vascular perspective. JAMA Ophthalmol 2013;131:36-43.

14. Burns A, lliffe S. Alzheimer's disease. BMJ 2009;338:b158.

15. Tiraboschi $P$, Hansen LA, Thal LJ, et al. The importance of neuritic plaques and tangles to the development and evolution of $A D$. Neurology 2004:62:1984-9.

16. Mallick J, Devi L, Malik PK, et al. Update on normal tension glaucoma. J Ophthalmic Vis Res 2016;11:204-8.

17. Berisha F, Feke GT, Trempe CL, et al. Retinal abnormalities in early Alzheimer's disease. Invest Ophthalmol Vis Sci 2007;48:2285-9.

18. Guo L, Duggan J, Cordeiro MF. Alzheimer's disease and retinal neurodegeneration. Curr Alzheimer Res 2010;7:3-14.

19. Kesler A, Vakhapova V, Korczyn AD, et al. Retinal thickness in patients with mild cognitive impairment and Alzheimer's disease. Clin Neurol Neurosurg 2011;113:523-6.

20. Sadun AA, Bassi CJ. Optic nerve damage in Alzheimer's disease. Ophthalmology 1990;97:9-17.

21. Vickers JC, Craig JE, Stankovich J, et al. The apolipoprotein epsilon4 gene is associated with elevated risk of normal tension glaucoma. Mol Vis 2002;8:389-93.

22. Liu YH, Tian T. Hypothesis of optineurin as a new common risk factor in normal-tension glaucoma and Alzheimer's disease. Med Hypotheses 2011;77:591-2.

23. Osawa T, Mizuno $\mathrm{Y}$, Fujita $\mathrm{Y}$, et al. Optineurin in neurodegenerative diseases. Neuropathology 2011;31:569-74.

24. Tamura H, Kawakami H, Kanamoto $\mathrm{T}$, et al. High frequency of openangle glaucoma in Japanese patients with Alzheimer's disease. $J$ Neurol Sci 2006;246(1-2):79-83.

25. Bayer AU, Ferrari F, Erb C. High occurrence rate of glaucoma among patients with Alzheimer's disease. Eur Neurol 2002;47:165-8.

26. Bayer AU, Keller ON, Ferrari F, et al. Association of glaucoma with neurodegenerative diseases with apoptotic cell death: Alzheimer's disease and Parkinson's disease. Am J Ophthalmol 2002;133:135-7.

27. Helmer $\mathrm{C}$, Malet $\mathrm{F}$, Rougier MB, et al. Is there a link between openangle glaucoma and dementia? The Three-City-Alienor cohort. Ann Neurol 2013;74:171-9.

28. Lin IC, Wang YH, Wang TJ, et al. Glaucoma, Alzheimer's disease, and Parkinson's disease: an 8-year population-based follow-up study. PLoS One 2014;9:e108938.

29. Bach-Holm D, Kessing SV, Mogensen U, et al. Normal tension glaucoma and Alzheimer disease: comorbidity? Acta Ophthalmol 2012;90:683-5

30. Ekström C, Kilander L. Open-angle glaucoma and Alzheimer's disease: a population-based 30-year follow-up study. Acta Ophthalmol 2017;95:e157-e158.

31. Lee SH, Kim GA, Lee W, et al. Vascular and metabolic comorbidities in open-angle glaucoma with low- and high-teen intraocular pressure: a cross-sectional study from South Korea. Acta Ophthalmol 2017:95:e564-e574.

32. Kessing LV, Lopez AG, Andersen PK, et al. No increased risk of developing Alzheimer disease in patients with glaucoma. J Glaucoma 2007:16:47-51.

33. Ou Y, Grossman DS, Lee PP, et al. Glaucoma, Alzheimer disease and other dementia: a longitudinal analysis. Ophthalmic Epidemiol 2012;19:285-92.

34. Keenan TD, Goldacre R, Goldacre MJ. Associations between primary open angle glaucoma, Alzheimer's disease and vascular dementia: record linkage study. Br J Ophthalmol 2015;99:524-7.

35. Kim KE, Park KH. Update on the prevalence, etiology, diagnosis, and monitoring of normal-tension glaucoma. Asia Pac J Ophthalmol 2016;5:23-31.

36. Hersi M, Irvine B, Gupta P, et al. Risk factors associated with the onset and progression of Alzheimer's disease: A systematic review of the evidence. Neurotoxicology 2017;61:143-87.

37. Stefanova E, Pavlovic A, Jovanovic Z, et al. Vascular risk factors in Alzheimer's disease - preliminary report. J Neurol Sci 2012;322(12):166-9.

38. Baptiste DC, Hartwick AT, Jollimore CA, et al. Comparison of the neuroprotective effects of adrenoceptor drugs in retinal cell culture and intact retina. Invest Ophthalmol Vis Sci 2002:43:2666-76.

39. Lee D, Kim KY, Noh YH, et al. Brimonidine blocks glutamate excitotoxicity-induced oxidative stress and preserves mitochondrial transcription factor a in ischemic retinal injury. PLoS One 2012;7:e47098

40. Osborne NN, DeSantis L, Bae JH, et al. Topically applied betaxolol attenuates NMDA-induced toxicity to ganglion cells and the effects of ischaemia to the retina. Exp Eye Res 1999;69:331-42.

41. Tatton W, Chen D, Chalmers-Redman R, et al. Hypothesis for a common basis for neuroprotection in glaucoma and Alzheimer's disease: anti-apoptosis by alpha-2-adrenergic receptor activation. Surv Ophthalmol 2003;48:S25-37.

42. Wood JP, DeSantis L, Chao HM, et al. Topically applied betaxolol attenuates ischaemia-induced effects to the rat retina and stimulates BDNF mRNA. Exp Eye Res 2001;72:79-86.

43. Lin JC, Hsu WC, Hsu HP, et al. Risk factors for vascular dementia: a hospital-based study in Taiwan. Acta Neurol Taiwan 2007;16:22-6.

44. Ahtiluoto S, Polvikoski T, Peltonen M, et al. Diabetes, Alzheimer disease, and vascular dementia: a population-based neuropathologic study. Neurology 2010;75:1195-202.

45. Ohara T, Doi Y, Ninomiya T, et al. Glucose tolerance status and risk of dementia in the community: the Hisayama study. Neurology 2011;77:1126-34.

46. Qiu C, Xu W, Winblad B, et al. Vascular risk profiles for dementia and Alzheimer's disease in very old people: a population-based longitudinal study. J Alzheimers Dis 2010;20:293-300.

47. Huang CC, Chung CM, Leu HB, et al. Diabetes mellitus and the risk of Alzheimer's disease: a nationwide population-based study. PLoS One 2014;9:e87095.

48. Chang $\mathrm{TJ}$, Jiang YD, Chang $\mathrm{CH}$, et al. Accountability, utilization and providers for diabetes management in Taiwan, 2000-2009: an analysis of the National Health Insurance database. J Formos Med Assoc 2012;111:605-16.

49. Li TC, Yang CP, Tseng ST, et al. Visit-to-visit variations in fasting plasma glucose and $\mathrm{HbA}_{1 \mathrm{c}}$ associated with an increased risk of alzheimer disease: Taiwan diabetes study. Diabetes Care 2017;40:1210-7.

50. Jain S, Aref AA. Senile dementia and glaucoma: evidence for a common link. J Ophthalmic Vis Res 2015;10:178-83.

51. Wostyn P, De Groot V, Van Dam D, et al. Senescent changes in cerebrospinal fluid circulatory physiology and their role in the pathogenesis of normal-tension glaucoma. Am J Ophthalmol 2013;156:5-14

52. Serot JM, Zmudka J, Jouanny P. A possible role for CSF turnover and choroid plexus in the pathogenesis of late onset Alzheimer's disease. J Alzheimers Dis 2012;30:17-26.

53. Preston JE. Ageing choroid plexus-cerebrospinal fluid system. Microsc Res Tech 2001;52:31-7.

54. Silverberg GD, Mayo M, Saul T, et al. Alzheimer's disease, normalpressure hydrocephalus, and senescent changes in CSF circulatory physiology: a hypothesis. Lancet Neurol 2003;2:506-11. 